\title{
Improving patient education about tobacco withdrawal and nicotine gum use by registered nurses in inpatient psychiatry: $A$ feasibility study
}

\section{Erin Muladore (D) | Jill A. Brown | Judy Haefner | Barbara Kupferschmid}

University of Michigan-Flint, Flint, Michigan

Correspondence

Erin Muladore, University of Michigan-Flint, Flint, MI.

Email: erin.muladore@gmail.com

\section{Accessible summary}

What is known on the subject?

- Many psychiatric inpatients use tobacco, but most psychiatric hospital units prohibit tobacco use. Psychiatric nurses do not receive adequate education about how to teach patients to best manage tobacco withdrawal symptoms.

What does this paper add to existing knowledge?

- Psychiatric nurses who receive a brief educational intervention about tobacco withdrawal symptoms and best practices for using nicotine gum may be more prepared to teach patients about these topics. In turn, patients may use nicotine gum more often during their hospitalization, leading to improved outcomes for them as well as for staff.

What are the implications for practice?

- A simple educational intervention aimed at psychiatric nurses can result in positive outcomes for psychiatric inpatients who use tobacco. Patients who have a positive experience with stopping tobacco use while hospitalized may be more likely to commit to lifelong tobacco cessation afterwards. The results of this feasibility study demonstrate that additional research that builds on the work presented here is warranted.

\section{Abstract}

Introduction: Tobacco use is prohibited in most psychiatric facilities in the United States, yet many psychiatric inpatients are tobacco users. Psychiatric nurses have reported inadequate education about best practices for managing tobacco dependence. Aim: To explore the feasibility of an educational intervention for psychiatric nurses designed to improve their ability to educate patients about best practices for managing tobacco dependence, as well as effective use of nicotine gum.

Method: Fourteen nurses on a psychiatric inpatient unit at a community hospital were educated about the targeted topics. Chart reviews of nonequivalent preintervention and post-intervention patient groups were conducted to explore the outcomes of the intervention.

Results: Patients received more teaching, and used nicotine gum more often, following the intervention. However, no statistically significant differences between the pre-intervention and post-intervention patient groups were found. 
Discussion: Educating nurses about best practices for managing tobacco withdrawal symptoms may have positive outcomes. Existing research suggests that such interventions may be most effective when support and structure are provided to ensure long-term practice changes.

Implications for practice: This feasibility study demonstrates that a brief nurse education intervention has the potential to improve the experience of tobacco withdrawal for psychiatric inpatients. Future research that expands upon the current project is warranted.

\section{KEYWORDS}

acute mental health, brief interventions, evidence-based practice, nurse education, tobacco

\section{1 | INTRODUCTION}

Tobacco use in the United States, the United Kingdom and Australia is two to four times higher among those with a diagnosed mental disorder than among the general population (Mendelsohn, Kirby, \& Castle, 2015; Prochaska, Das, \& Young-Wolff, 2017; Prochaska, Hall, Delucchi, \& Hall, 2014). In the United States, while most psychiatric facilities prohibit smoking on their premises (Prochaska et al., 2017), approximately $44 \%$ of tobacco users have a mental health diagnosis (Prochaska, Gill, \& Hall, 2004) and between $42 \%$ and $60 \%$ of admitted inpatients are current smokers (Leyro et al., 2013). Thus, many of those admitted to inpatient units struggle to remain tobacco free during their hospitalization. Since the half-life of nicotine is about 2 hrs, symptoms of withdrawal from tobacco products typically begin within 24 hrs of the last use (American Psychiatric Association [APA], 2013; Robson et al., 2017). Fifty per cent of tobacco users develop withdrawal symptoms following cessation, meaning that least $22 \%$ of those admitted for inpatient psychiatric treatment will likely experience tobacco withdrawal concurrent with a psychiatric crisis (APA, 2013). This sets the stage for a multitude of potential challenges for patients and staff, as described later in this paper.

As of 2011, the average length of stay for a psychiatric admission in the United States was 5 or 6 days (Glick, Sharfstein, \& Schwartz, 2011). Patients who experience tobacco withdrawal as a consequence of psychiatric hospitalization will likely endure the worst of these symptoms during inpatient treatment for comorbid mental health issues, so optimal management of withdrawal symptoms is essential.

Abstinence from tobacco products results in a pattern of withdrawal symptoms that begins as wanting, progresses to craving and ends with a need to use again (DiFranza, Ursprung, \& Biller, 2012). These symptoms can begin as rapidly as a few hours after nicotine abstinence, peak between 2 and 7 days, and may continue for 10 days to 1 month (APA, 2013; McLaughlin, Dani, \& De Biasi, 2015; Paolini \& De Biasi, 2011; Soyster, Anzai, Fromont, \& Prochaska, 2016). Cravings-which involve a persistent desire to use tobacco, unpleasant physical sensations, and disrupted concentration-are at their most intense shortly after a quitting attempt but can linger for years even for those who have successfully quit using tobacco (Carpenter et al., 2013; Hughes, 2010).

During detoxification from a substance such as tobacco, abstinence may or may not be a goal of the user (Diaper, Law, \& Melichar, 2013). In the case of inpatients who are not allowed to smoke, detoxification is a consequence of hospital policy rather than a selfselected and self-directed step towards long-term abstinence. Therefore, patients in the psychiatric inpatient setting may struggle not only with the symptoms of tobacco withdrawal, but also with finding motivation to participate in managing their withdrawal. However, patients admitted to the hospital for inpatient psychiatric treatment benefit most when they are actively engaged in decisionmaking about their care, including engaging in tobacco cessation (Duncan et al., 2016).

The effects of tobacco withdrawal are somatic, cognitive and affective and the experience is well-known to be challenging even for those without mental illness (Frandsen, Thorpe, Shiffman, \& Ferguson, 2017). These symptoms can be so severe that coping with them has been equated with enduring a psychiatric crisis (Frandsen et al., 2017). As a result, many people addicted to tobacco continue to use it rather than face the formidable difficulties that come with quitting. For patients admitted to an inpatient psychiatric unit, the simultaneous combination of coping with a psychiatric crisis and involuntary abstinence from tobacco can result in acute stress that manifests physically, mentally and emotionally (Frandsen et al., 2017). In light of this clinical picture, the need to address tobacco withdrawal in the inpatient setting becomes abundantly clear.

Having a mental illness increases the likelihood of experiencing symptoms of withdrawal when abstaining from tobacco (APA, 2013; Ameringer \& Leventhal, 2015; Leventhal, Ameringer, Osborn, Zvolensky, \& Langdon, 2013; Smith, Homish, Giovino, \& Kozlowski, 2014; Soyster et al., 2016). Individuals with psychiatric disorders may be unusually sensitive to tobacco cessation, leading to withdrawal symptoms that occur sooner after abstinence than in those without psychiatric diagnoses (Ameringer \& Leventhal, 2015). Those with depressive disorders, anxiety disorders, bipolar disorders, attentiondeficit/hyperactivity disorder and other substance use disorders are 
most likely to experience severe symptoms of tobacco withdrawal (APA, 2013).

Tobacco withdrawal symptoms are believed to be caused by decreased levels of both dopamine and norepinephrine (Kawai et al., 2017). Irregularities in these catecholamines are also involved in many psychiatric diagnoses, including depressive and anxiety disorders, bipolar disorder, schizophrenia and gambling disorder (Cousins, Butts, \& Young, 2009; Felger \& Lotrich, 2013; Hook et al., 2014; Mittal et al., 2017; Potenza, 2013). The fact that dysregulations in these neurotransmitters are involved in both tobacco withdrawal and psychiatric disorders fortifies the argument that tobacco withdrawal is more complex for tobacco users with comorbid psychiatric disorders than for those without (APA, 2013; Reynolds, McGowan, \& Dalton, 2013; Yamamoto, Shinba, \& Yoshii, 2014). Given the physiologic factors involved, these patients may have trouble controlling their actions; even a brief period of tobacco withdrawal can result in a heightened neural response to stress (Ashare et al., 2016). This complex interplay between the symptoms of psychiatric disorders and the symptoms of tobacco withdrawal point to the need to educate and support inpatients experiencing both causes of symptoms during hospitalization.

The affective signs and symptoms of tobacco withdrawal are not specific to tobacco withdrawal itself (DiFranza \& Ursprung, 2008). They are often similar or identical to the signs and symptoms of a variety of psychiatric disorders (APA, 2013). DiFranza and Ursprung (2008) raised the question of how clinicians can be certain that tobacco users are correctly differentiating the affective symptoms of tobacco withdrawal from affective states unrelated to withdrawal. They concluded that because tobacco users experience withdrawal symptoms repeatedly and because these symptoms resolve with tobacco use, smokers know exactly when they are experiencing tobacco withdrawal (DiFranza \& Ursprung, 2008).

Signs and symptoms caused by tobacco withdrawal include irritability, frustration, anger, anxiety, difficulty concentrating, increased appetite, restlessness, depressed mood and insomnia (APA, 2013; Frandsen et al., 2017). While most common among daily users, withdrawal symptoms can occur even among those who use tobacco on a less than daily basis (APA, 2013). The overlap between these symptoms and those of other mental disorders can result in a lack of clarity with regard to assessment, patient care and treatment plans (Leyro et al., 2013; Soyster et al., 2016). Additionally, according to the DSM-5 tobacco use can increase the serum levels of many psychotropic medications, which can also lead to clinically significant outcomes (APA, 2013). Thus, tobacco cessation that is inadequately managed in the inpatient psychiatric setting is an issue which needs to be addressed for patients, clinicians and registered nurses (RNs).

Staff working with patients in inpatient psychiatric settings need to be aware that symptoms attributed to psychiatric disorders can be caused by tobacco withdrawal, and vice versa; it is common for symptoms of the two to be confounded during the assessment process (APA, 2013; Ameringer \& Leventhal, 2015; Leventhal et al., 2013; McLaughlin et al., 2015; Robson et al., 2017; Smith et al., 2014; Soyster et al., 2016). As a result, when tobacco withdrawal is treated inadequately during hospitalization, psychiatric diagnoses may be incorrect or incomplete (Soyster et al., 2016). Tobacco withdrawal also introduces the possibility that inaccurate assessment of treatment efficacy will occur. Patients who are required to stop using tobacco at the time of hospitalization may experience a gradual decrease in tobacco withdrawal symptoms following an initial period of acute exacerbation (Soyster et al., 2016). When this occurs, these diminished symptoms may be attributed to the treatment provided for the admitting diagnoses rather than to an improvement in the symptoms of tobacco withdrawal (Soyster et al., 2016). A diagnosis of tobacco withdrawal can be confirmed in the case of symptoms that decrease with the use of nicotine replacement therapy (NRT; APA, 2013).

Both patients and staff RNs must understand that treating the acute symptoms of tobacco withdrawal is a collaborative task. Ideally, nurses educate patients about tobacco withdrawal and options available to treat it, while patients exercise these options in ways that are most effective for them. Unfortunately, recent research demonstrated that levels of NRT received by patients on psychiatric units are often suboptimal; additionally, psychiatric RNs reported that they did not have enough training to provide these medications in an effective manner (Thomas \& Richmond, 2017). Thomas and Richmond (2017) called for the implementation of staff training for managing tobacco dependence among psychiatric inpatients. The clinical guideline published by the United States Department of Health and Human Services (USDHHS, 2008) offers one of the most recent sets of recommendations for NRT use. Evidence has demonstrated that higher-dose nicotine patches, gum and lozenges are the most efficacious for highly dependent patients; a combination of NRT products may be particularly helpful for this population (USDHHS, 2008).

There is a need to ensure that staff RNs are educated about the signs and symptoms of tobacco withdrawal and how these may contribute to patient behaviours that interfere with the ability to fully engage in treatment. Staff RNs working with these patients also need to understand the ways in which the symptoms of tobacco withdrawal can lead to incorrect or incomplete diagnoses, as well as inaccurate assessments of treatment efficacy for psychiatric disorders. Equipped with this information, RNs will be prepared to educate patients about the consequences of tobacco withdrawal as well as about best practices for managing it during hospitalization.

While protocols exist to assist clinicians with choosing the appropriate type, route, schedule and dosage of NRT for patients, decisions about whether and how often to make use of prn (as-needed) forms of NRT are typically made by patients at the discretion of nursing staff. If NRT is not ordered, if patients make inadequate use of the prn NRT regimen available to them, or if the type of nicotine replacement necessary to meet a patient's needs is not available, patients are likely to struggle with the sequelae of tobacco withdrawal during their hospitalization. In extreme cases, patients have been known to elope from the hospital in order to resume smoking (Stiebel \& Nightengale, 2013). In other serious cases, patients are put into seclusion or restraints due to behaviours that are rooted in 
unbearable withdrawal symptoms caused by the abrupt cessation of nicotine (Belluck, 2013; Lawn \& Pols, 2003; Stiebel \& Nightengale, 2013).

Nicotine gum is considered a "rescue medication" for smokers experiencing intense cravings for nicotine and is one of the best options available for the management of acute symptoms of withdrawal (Mendelsohn, 2013; Shiffman et al., 2003; USDHHS, 2008). It is a broadly-accepted form of NRT due to its safety, familiarity, and the fact that users have control over the timing of its effects vis-avis their acute nicotine cravings (Shiffman et al., 2009). Additionally, it is effective both physically and psychologically; Shiffman et al. (2003) demonstrated that nicotine gum was effective in reducing cravings and that the mechanism was pharmacological, not merely behavioural.

Tobacco users are accustomed to self-regulating their dose of nicotine throughout the course of the day, and to experiencing the effects of nicotine intake within seconds of ingestion (Frandsen et al., 2017; Schneider et al., 2006; USDHHS, 2014). Smoking allows tobacco to be absorbed through the arterial blood stream and enables nicotine to reach the brain almost instantaneously; in contrast, NRT products are absorbed through the systemic venous system and thus require minutes to hours to take effect (Molyneux, 2004; Subramaniyan \& Dani, 2015). However, nicotine gum is one of the faster forms of NRT, controlling acute cravings within 15-20 min of initiation of use (Shiffman et al., 2009).

Despite taking longer to mitigate the symptoms of tobacco withdrawal than can be accomplished with smoking, nicotine gum has been theorized to be effective in reducing symptoms of tobacco withdrawal including irritability, anxiety, poor concentration, sleep disturbance, hunger, craving for nicotine and overall withdrawal discomfort (Mendelsohn, 2013; West \& Shiffman, 2001). In one study of psychiatric inpatients who resumed smoking following hospitalization, 70\% made use of NRT during their hospital admission (Prochaska, Fletcher, Hall, \& Hall, 2006). These patients identified nicotine replacement medications as being beneficial for their effects on the symptoms of tobacco withdrawal rather than for their potential to assist with smoking cessation (Prochaska et al., 2006). For patients who require management of the acute effects that occur with abrupt cessation of tobacco use, nicotine gum is an essential intervention whose importance must not be overlooked.

Given the existing knowledge about the interplay between psychiatric illnesses and tobacco use, the ongoing lack of training for RNs about the use of nicotine replacement medications in this patient population, and the availability of a commonly available and low-risk rescue medication whose use can be optimized as a partial solution to the many challenging sequelae of tobacco withdrawal among patients admitted to inpatient psychiatric units, an exploratory study designed to investigate the feasibility of a randomized controlled trial was identified as a project that would add value to the psychiatric and mental health nursing literature.

\section{I RESEARCH AIM/QUESTION}

Following Tickle-Degnen (2013), our overarching objective was to understand the factors that might arise in conducting a more rigorous and larger-scale study of a RN-driven patient education intervention related to tobacco withdrawal and nicotine gum use in the inpatient psychiatric setting. To this end, the specific purpose of our feasibility study was twofold: first, to educate staff RNs working on a behavioural health unit at a medium-sized community hospital in the United States about (a) the signs and symptoms of tobacco withdrawal, (b) the process of requesting nicotine gum on a prn basis for the treatment of acute symptoms of tobacco withdrawal and (c) best practices for using nicotine gum. Second, we aimed to increase $\mathrm{RN}$-provided patient education on these same topics as evidenced by increased documentation by nurses. We also wanted to understand whether patients who received this education would request nicotine gum more often as compared with an equivalent patient population during an equivalent, pre-intervention period of time.

The organization has a hospital-wide nursing policy which addresses assisting patients with reducing or stopping smoking, based on a clinical practice guideline published by the U.S. Public Health Service (USDHHS, 2008) and additional information published by an equivalent organization at the statewide level. The policy outlines the 5 As Model for treating tobacco use and dependence but does not indicate when or how often patient teaching should occur. Although the policy specifies that RNs providing this education should document their interventions, it was observed that charting related to patient education about tobacco use and NRT varied greatly from nurse to nurse. In addition, it was noted that there was no area in the electronic chart specifically designated for documenting such education.

This feasibility study entailed implementation of an educational intervention for psychiatric nurses working with inpatients enduring comorbid tobacco withdrawal and possible exacerbation of psychiatric symptoms. In so doing, this project aimed to provide insight into the extent to which this education of RNs about tobacco withdrawal and the use of nicotine gum to treat acute cravings for tobacco would result in increased patient education about these topics, as well as an increase in the use of nicotine gum to manage acute symptoms of tobacco withdrawal.

\section{3 | METHODS}

\section{1 | Participants}

The nurse participants in this project were the staff RNs on a 24bed psychiatric inpatient unit at a medium-sized community hospital in Southeastern Michigan. Fourteen RNs (56\%) of the 25 nurses on staff participated in the project. Exclusion criteria were RNs who did not work a shift during the post-intervention phase and those who declined to participate. 
Patient participants consisted of a pre-intervention comparison group and a post-intervention group. All patients were adults age 18 and older who were hospitalized on the unit during the preintervention or post-intervention phases and had used a tobacco product within the 30 days preceding their admission. The 30 -day window was derived from the definition of tobacco use specified in the tobacco treatment measure set of The Joint Commission (2017; Smith, Cobb, \& Corso, 2013).

\section{2 | Ethical considerations}

Each nurse participant signed an agreement providing informed consent to participate in the study, acknowledging that they were under no obligation to take part in the project and that the data would be confidential. All data related to patients were acquired through chart reviews. Project leaders were trained in responsible conduct of research by completing certification through the University of Michigan Program for Education and Evaluation in Responsible Research and Scholarship. The study protocol was determined to be a quality improvement project and was therefore granted exemption status by the institutional review board of the participating hospital and the University of MichiganFlint Institutional Review Board. This project also complied with SQUIRE 2.0 standards.

\section{3 | Procedures}

\subsection{1 | Data collection}

The project consisted of a pre-intervention and post-intervention phase of 31 days each. The pre-intervention phase took place primarily during January 2018, while the post-intervention phase spanned mid-February to mid-March, 2018. Data were collected about all instances of staff RN documentation of patient teaching about the aforementioned topics. In addition, data about the frequency, dosing and timing of nicotine gum administrations were also collected, as well as limited demographic information about patients who met the inclusion criterion of being a recent tobacco user. All data were de-identified to protect the privacy of the RNs and patients involved.

\subsection{2 | RN education intervention}

The study intervention consisted of educating staff RNs about how to teach psychiatric inpatients about (a) the signs and symptoms of tobacco withdrawal, (b) the process of requesting nicotine gum on a prn basis for the treatment of acute symptoms of tobacco withdrawal and (c) best practices for using nicotine gum. RNs who consented to participate in the project were instructed about the details of their role in the project, as well as the underlying rationales for the information to be taught to patients.

RNs were educated during a session held on the unit during the time designated for a regularly scheduled staff meeting. Two brief videos, one summarizing the pathophysiology of tobacco withdrawal and the other explaining the pharmacodynamics of NRT (Quit Victoria, 2017a, 2017b), were viewed by the RN participants to refresh their knowledge in these areas. RNs were then provided with a handout to use when educating patients about tobacco withdrawal and nicotine gum use. Nurses were instructed to provide each patient with a copy of the handout within $24 \mathrm{hrs}$ of arrival on the unit, and suggestions about how to teach the information were provided and discussed. RNs were asked to obtain teach-back from patients. Teach-back is a method that entails having patients restate information in their own words to confirm that it has been understood correctly (Agency for Healthcare Research and Quality, n.d.).

Nurse participants were then educated about the need to document their patient teaching, and given verbal instructions and a handout with specific instructions about how and where to chart this information in the electronic health record. RN participants were reminded that they should chart only what they taught so their documentation would accurately reflect the patient teaching that took place.

\section{4 | RESULTS}

This study used a nonequivalent groups pretest-posttest design to compare pre-intervention control data with equivalent postintervention data.

\section{1 | Patient characteristics}

Characteristics of the patients whose charts were reviewed are presented in Table 1. Data about tobacco use were based on what was available for each patient. Of note, many of the tobacco use histories completed by nurses at admission were incomplete to varying degrees.

The pre-intervention group consisted of 24 patients with ages ranging from 18 to 69 years. The most common categories of psychiatric diagnoses assigned during the current admission for these patients were substance use disorders (54.2\%), depressive disorders (50.0\%) and anxiety disorders (37.5\%). The ages at which these patients began using tobacco ranged from 11 to 18 , with all but one patient in this group being cigarette smokers (95.8\%). Only one patient (4.2\%) used more than one form of tobacco. The number of packs (defined as 20 cigarettes) per day for cigarette smokers ranged from 0.2 to 2 . The number of years of tobacco use varied widely, from 3 to 45 years. The average inpatient length of stay for this group was 4.7 days.

The post-intervention group had 30 patients who spanned 19-66 years of age. The three most common categories of psychiatric diagnoses during their admission to the unit were depressive disorders (70.0\%), anxiety disorders (46.7\%) and substance use disorders (43.3\%). These patients began using tobacco from ages 9 through 40 years. All but two used cigarettes, while three patients in 
TABLE 1 Sample characteristics by group

\begin{tabular}{|c|c|c|c|c|c|c|}
\hline Variable & \multicolumn{2}{|c|}{ Total $(N=54)$} & \multicolumn{2}{|c|}{ Pre-intervention $(n=24)$} & \multicolumn{2}{|c|}{ Post-intervention $(n=30)$} \\
\hline \multicolumn{7}{|l|}{ Gender } \\
\hline Female & 24 & 44.4 & 11 & 45.8 & 13 & 43.3 \\
\hline Male & 30 & 55.5 & 13 & 54.2 & 17 & 56.7 \\
\hline \multicolumn{7}{|l|}{ Age } \\
\hline$\geq 35$ & 23 & 42.6 & 9 & 37.5 & 14 & 46.7 \\
\hline \multicolumn{7}{|l|}{ Psychiatric diagnosis } \\
\hline Anxiety disorder & 23 & 42.6 & 9 & 37.5 & 14 & 46.7 \\
\hline Depressive disorder & 33 & 61.9 & 12 & 50.0 & 21 & 70.0 \\
\hline Cigars & 3 & 5.6 & 2 & 8.3 & 1 & 3.3 \\
\hline Chewing tobacco & 2 & 3.7 & 0 & 0 & 2 & 6.7 \\
\hline E-cigarettes & 2 & 3.7 & 0 & 0 & 2 & 6.7 \\
\hline \multirow[t]{2}{*}{$>1$ form of tobacco } & 4 & 7.4 & 1 & 4.2 & 3 & 10.0 \\
\hline & $M$ & $S D$ & M & $S D$ & M & $S D$ \\
\hline Age of smoking initiation & 16 & 5.1 & 15.1 & 1.9 & 16 & 6.7 \\
\hline Cigarette packs per day & 0.9 & 0.5 & 0.9 & 0.5 & 0.9 & 0.5 \\
\hline Years of tobacco use & 17 & 11.1 & 19 & 14.6 & 15.8 & 9.2 \\
\hline
\end{tabular}

the group used more than one form of tobacco. The quantity of cigarettes smoked ranged from 0.2 to 2 packs per day, and the ages at which they began smoking ranged from 9 to 40 years. The durations for which they had used tobacco ranged from 3 to 45 years. The average inpatient length of stay for this group was 6.5 days.

A summary of patient outcomes describing the number and percentage of patients who received nicotine gum only, patient education only, or both, is presented in Table 2.

\subsection{RN documentation of patient education}

During the pre-intervention phase of the project, RNs documented just one instance of teaching about any of the topics that were included in the RN education intervention. This teaching consisted of educating one patient (4.2\%) about the use of nicotine patches. Following the RN education intervention, this number increased with seven patients $(23.3 \%)$ in the post-intervention group being educated about the three topics that were the focus of the education intervention provided to RNs.

\section{3 | NRT use}

On the psychiatric inpatient unit where the project took place, nicotine gum is available in a $2 \mathrm{mg}$ dose. One or two pieces of gum are given per administration, depending on the dose ordered by the
TABLE 2 Outcomes by group

\begin{tabular}{|c|c|c|c|c|}
\hline \multirow[b]{2}{*}{ Variable } & \multicolumn{2}{|c|}{$\begin{array}{l}\text { Pre-intervention } \\
(n=24)\end{array}$} & \multicolumn{2}{|c|}{$\begin{array}{l}\text { Post- } \\
\text { intervention } \\
(n=30)\end{array}$} \\
\hline & $n$ & $\%$ & $n$ & $\%$ \\
\hline $\begin{array}{l}\text { Patients receiving teaching } \\
\text { only }\end{array}$ & 1 & 4.2 & 7 & 23.3 \\
\hline $\begin{array}{l}\text { Patients receiving nicotine } \\
\text { gum only }\end{array}$ & 12 & 50.0 & 21 & 70.0 \\
\hline $\begin{array}{l}\text { Patients receiving teaching } \\
\text { and nicotine gum }\end{array}$ & 0 & 0.0 & 6 & 20.0 \\
\hline
\end{tabular}

prescribing physician. All nicotine gum administered on the unit occurs on a prn basis, meaning that patients use it when they feel it is appropriate or when its use is suggested by an $\mathrm{RN}$ and the patient is in agreement. NRT is also available in the form of nicotine patches, in doses of 21, 14 and $7 \mathrm{mg}$; when ordered, this medication is administered on a daily basis with patients having the right to refuse its use. Nicotine patches and nicotine gum may be used individually or together, at the discretion of the prescriber. During the pre-intervention phase, a total of 215 administrations of nicotine gum occurred. They were divided between 203 ( $94.4 \%$ of total administrations) at the $2 \mathrm{mg}$ dose and 12 (5.6\%) at the $4 \mathrm{mg}$ dose. In contrast, during the post-intervention phase, RNs supplied 248 
doses of nicotine gum to patients. 185 (74.6\% of total administrations) of these were in the amount of $2 \mathrm{mg}$, while the remaining 63 (25.4\%) were $4 \mathrm{mg}$.

\subsection{Statistical analysis}

Data were cross-tabulated and analysed for statistical significance using SPSS. The Pearson chi-squared test and Fisher's exact test were used as appropriate to understand whether the relationships between specific variables were statistically significant pre- and post-intervention. An alpha level of 0.05 was used to assess statistical significance for all analyses.

A chi-squared test revealed that there was no statistically significant difference between the pre-intervention and postintervention groups in terms of gender or age. The pre-intervention group was $45.8 \%$ female, while the post-intervention group was $43.3 \%$ female $(p=0.854)$. Individuals under age 35 comprised $62.5 \%$ of the pre-intervention group as compared with $53.3 \%$ of the post-intervention group $(p=0.498)$. In terms of psychiatric diagnoses, a chi-squared test revealed that, although the differences between the groups were not statistically significant, with $p=0.462$ for substance use disorders and $p=0.713$ for anxiety disorders, the $p$-value of 0.073 for depressive disorders was notable given that it approached statistical significance. Diagnoses were considered on a standalone basis, and the presence of multiple psychiatric diagnoses in individual patients was not included as part of the statistical analysis.

A Fisher's exact test revealed that there were no statistically significant differences between pre-intervention and post-intervention patients in terms of the type of tobacco used. Cigarette $(p=1.000)$, cigar $(p=0.579)$, chewing tobacco $(p=0.497)$, and e-cigarette ( $p=0.497$ ) use were all examined. Similarly, there was no statistical difference between the two groups among those who used more than one form of tobacco; using Fisher's exact test to test this comparison yielded $p=0.620$.

Patients in the pre-intervention group were compared with patients in the post-intervention group in terms of the percentage for whom documentation of teaching by an RN about tobacco withdrawal and nicotine gum use occurred. Fisher's exact test revealed no statistically significant difference between the groups for this factor, with $4.2 \%$ receiving teaching prior to the intervention and $23.3 \%$ receiving teaching after $(p=0.063)$. The chi-squared test was used to compare the percentages of patients who received nicotine gum before and after the RN education intervention. In the preintervention group, $50.0 \%$ of patients received nicotine gum while $70.0 \%$ of those in the post-intervention group were administered this medication $(p=0.134)$. An additional cross-tabulation was created to compare patients who received both $\mathrm{RN}$ teaching and nicotine gum. There was a shift from the pre-intervention phase to the post-intervention phase in that more patients received both teaching and gum after the intervention than before. Given that fewer than five patients were in each of these groups, a $p$-value cannot be reported for this comparison. For patients who received either teaching or gum, no statistically significant difference was found using a chi-squared test ( $p=0.143$ ).

\section{5 | DISCUSSION}

This study was planned with the primary goal of evaluating the feasibility of additional research on $\mathrm{RN}$-led efforts to educate psychiatric inpatients about tobacco withdrawal and the use of nicotine gum to reduce the negative outcomes that can result from undertreatment of tobacco withdrawal symptoms. As such, the project involved the implementation of an education intervention for RNs in order to investigate its effects on two quality improvement-based outcomes: documentation of teaching about tobacco withdrawal and its symptoms as well as best practices for nicotine gum use; and nicotine gum use by psychiatric inpatients. By examining these outcomes, we aimed to provide insight into the extent to which education provided by nurses to patients enduring comorbid tobacco withdrawal and exacerbation of psychiatric symptoms would be useful for helping psychiatric inpatients manage acute withdrawal symptoms.

Although our analysis revealed that there was no statistically significant difference between the pre-intervention and postintervention patients with regard to documentation of teaching by $\mathrm{RNs}$, there was a notable increase of $19.1 \%$ in the number of patients who received teaching (one pre-intervention patient, as compared with seven post-intervention patients). Similarly, there was an increase, although not statistically significant, in the percentage of patients who received nicotine gum following the intervention. $50.0 \%$ of pre-intervention patients received nicotine gum, while $70.0 \%$ received this medication after the intervention for an increase of $20.0 \%$. Finally, although the number of patients who received both teaching and nicotine gum was not statistically significant, there was a marked increase of $20.0 \%$; 0 pre-intervention patients received both, while six post-intervention patients were in this category.

Wye, Stockings, Bowman, Oldmeadow, and Wiggers (2017) demonstrated that provision of training, education and feedback to clinical staff resulted in long-term practice changes in terms of tobacco use assessment, provision of advice on cessation and prescribing of NRT to psychiatric inpatients both during admission and at discharge. Their study included a practice change support officer who managed the implementation of project strategies and resources (Wye et al., 2017), suggesting that staff asked to add new tasks to their practice may be most successful with structure and support beyond what we were able to provide.

It is possible that RNs participating in this project performed patient education on the target topics more often than was documented; the results in Table 2 speak to the likelihood that there was a discrepancy between what nurses did and what they documented doing. Myklebust, Bjørkly, and Råheim (2017) described the gap that exists between the care psychiatric nurses provide to patients and how (and whether) they document that care. According to Lewin's classic force field model, one of the requirements for change is that participants link motivation to action (Lewin, 1947). Given the 
short-term nature of this project, nurses on the unit may have lacked sufficient motivation to take action and perform the additional tasks of patient teaching about the areas of focus. Alternatively, it is possible that some nurses participating in the project taught patients about the topics addressed in the nurse education intervention but neglected to document that teaching.

\section{1 | Limitations}

There were some obvious limitations in the design of our study that affected the interpretations of the data we collected. Given the time-limited nature of the pre- and post-intervention phases, our sample sizes were ultimately too small to yield statistically significant results. Despite this, some intriguing trends emerged. A future study of longer duration would offer the opportunity to re-examine this topic with a larger group of patients, thus providing additional insight into the issues we examined.

The use of chart reviews to measure patient teaching was another limiting factor to the study. Although the use of chart reviews to measure whether patient teaching occurred is common practice in healthcare research, there are a number of disadvantages, including incomplete and missing data (Gregory \& Radovinsky, 2012); these were factors in our study. Our reliance on chart reviews also precluded us from following up with patients following their discharge, which might have revealed longer-term outcomes related to the study. Additional measures of whether patient teaching occurred could have included direct observation of patient teaching, or patient report, although these methods would present their own challenges.

\section{6 | IMPLICATIONS FOR PRACTICE}

This project was intended as a feasibility study and was carried out at a community hospital in the United States. For these reasons, the results should not be generalized to other settings. However, our findings have implications for psychiatric inpatient units worldwide. Given that tobacco is universally harmful-and fatal for a third of its users-abstinence from it is a goal that applies equally to those with psychiatric diagnoses and those without (Basu, Mitra, \& Vadivelu, 2015). There has been increased recognition in the scientific literature of the inequities of tobacco treatment that have persisted between psychiatric populations and the general public (Prochaska et al., 2017). This continues to be the case despite clinical practice guidelines and standards of care issued by accrediting bodies and professional organizations which emphasize the need to treat tobacco dependence among patients with psychiatric disorders (APA, 2010; USDHHS, 2008). Therefore, both clinicians and nurses must take seriously the imperative to fully address the sequelae of tobacco cessation that occur for many patients during inpatient psychiatric hospitalization.

Our study highlights the fact that a brief educational intervention using minimal resources, directed at RNs, has the potential to improve the experience of tobacco withdrawal for psychiatric inpatients. Improved patient and unit outcomes can be achieved through an increased focus on the vital roles patient education and nicotine gum-a rescue medication for tobacco withdrawalplay in the overall clinical picture for this population. While our study did not focus on long-term cessation from tobacco, a positive experience with managing the symptoms of tobacco withdrawal during hospitalization may empower patients to pursue this as a long-term goal. Based on the findings of this feasibility study, future research exploring the role of $\mathrm{RN}$ education as related to patient teaching about management of tobacco withdrawal symptoms during inpatient psychiatric hospitalization is warranted. Larger sample sizes (of both patients and nurses), longer-term studies, and those incorporating follow-up with patients would all be useful next steps that would help expand on the results of this project.

Hospitalization due to psychiatric illness is a stressful event. For patients who use tobacco, the requirement that they abstain from engaging in a tried-and-true coping mechanism while dealing with the aftermath of a psychiatric crisis poses an additional challenge. While cessation from tobacco is the ultimate tobacco-related goal for these patients, the primary goal during hospitalization should be that of optimizing management of any withdrawal symptoms that arise during this time. From there, patients will be better positioned to work with outpatient mental health providers to commit to, and achieve success with, lifelong tobacco cessation.

\section{7 | RELEVANCE STATEMENT}

This feasibility study highlights the fact that a brief intervention using minimal resources, directed at registered nurses, has the potential to improve the experience of tobacco withdrawal for psychiatric inpatients. Improved patient and unit outcomes may be achieved through an increased focus on the vital roles that patient education and nicotine gum-a rescue medication for tobacco withdrawal-play in the overall clinical picture for this population. A positive experience with managing the symptoms of tobacco withdrawal during hospitalization may empower patients to pursue tobacco cessation as a long-term goal.

\section{ORCID}

Erin Muladore iD http://orcid.org/0000-0003-2846-2031

\section{REFERENCES}

Agency for Healthcare Research and Quality. (n.d.). Teach-back: A guide for staff. Retrieved from https://www.ahrq.gov/sites/default/files/ wysiwyg/professionals/quality-patient-safety/patient-family-engagement/pfeprimarycare/teach-back-guideforstaff.pdf

American Psychiatric Association. (2010). Practice guideline for the treatment of patients with substance use disorders (2nd ed.). Retrieved 
from https://psychiatryonline.org/pb/assets/raw/sitewide/practice guidelines/guidelines/substanceuse.pdf

American Psychiatric Association (2013). Diagnostic and statistical manual of mental disorders (5th ed.). Arlington, VA: American Psychiatric Publishing.

Ameringer, K. J., \& Leventhal, A. M. (2015). Psychological symptoms, smoking lapse behavior, and the mediating effects of nicotine withdrawal symptoms: A laboratory study. Psychology of Addictive Behaviors, 29(1), 71-81. https://doi.org/10.1037/adb0000029

Ashare, R. L., Lerman, C., Cao, W., Falcone, M., Bernardo, L., Ruparel, K., \& Loughead, J. (2016). Nicotine withdrawal alters neural responses to psychosocial stress. Psychopharmacology, 233(13), 2459-2467. https://doi.org/10.1007/s00213-016-4299-5

Basu, D., Mitra, S., \& Vadivelu, N. (2015). Tobacco. In A. D. Kaye, N. Vadivelu \& R. D. Urman (Eds.), Substance abuse: Inpatient and outpatient management for every clinician (pp. 89-107). https://doi. org/10.1007/978-1-4939-1951-2_9

Belluck, P. (2013, February 6). Smoking, once used to reward, faces a ban in mental hospitals. The New York Times. Retrieved from http:// www.nytimes.com/2013/02/07/health/psychiatric-hospitals-alter-rules-on-patient-smoking.html

Carpenter, M., Jardin, B., Burris, J., Mathew, A., Schnoll, R., Rigotti, N., \& Cummings, K. (2013). Clinical strategies to enhance the efficacy of nicotine replacement therapy for smoking cessation: A review of the literature. Drugs, 73(5), 407-426. https://doi.org/10.1007/ s40265-013-0038-y

Cousins, D. A., Butts, K., \& Young, A. H. (2009). The role of dopamine in bipolar disorder. Bipolar Disorders, 11(8), 787-806. https://doi. org/10.1111/j.1399-5618.2009.00760.x

Diaper, A. M., Law, F. D., \& Melichar, J. K. (2013). Pharmacological strategies for detoxification. British Journal of Clinical Pharmacology, 77(2), 302-314. https://doi.org/10.1111/bcp.12245

DiFranza, J. R., \& Ursprung, W. W. S. A. (2008). The latency to the onset of nicotine withdrawal: A test of the sensitization-homeostasis theory. Addictive Behaviors, 33(9), 1148-1153. https://doi.org/10.1016/j. addbeh.2008.04.011

DiFranza, J. R., Ursprung, W. W. S., \& Biller, L. (2012). The developmental sequence of tobacco withdrawal symptoms of wanting, craving and needing. Pharmacology, Biochemistry, and Behavior, 100(3), 494-497. https://doi.org/10.1016/j.pbb.2011.10.018

Duncan, G. N., Ahmed, A. O., Mabe, P. A., Anderson, B., Fenley, G., \& Rollock, M. (2016). Shared decision-making. In N. N. Singh, J. W. Barber \& S. Van Sant (Eds.), Handbook of recovery in inpatient psychiatry (pp. 99-123). Cham, Switzerland: Springer. https://doi. org/10.1007/978-3-319-40537-7_5

Felger, J. C., \& Lotrich, F. E. (2013). Inflammatory cytokines in depression: Neurobiological mechanisms and therapeutic implications. Neuroscience, 246, 199-229. https://doi.org/10.1016/j. neuroscience.2013.04.060

Frandsen, M., Thorpe, M., Shiffman, S., \& Ferguson, S. G. (2017). A clinical overview of nicotine dependence and withdrawal. In F. S. Hall, J. W. Young \& A. Der-Avakian (Eds.), Negative affective states and cognitive impairments in nicotine dependence (pp. 205-215). Amsterdam, The Netherlands, Elsevier. https://doi.org/10.1016/ b978-0-12-802574-1.00012-0

Glick, I. D., Sharfstein, S. S., \& Schwartz, H. I. (2011). Inpatient psychiatric care in the $21^{\text {st }}$ century: The need for reform. Psychiatric Services, 62(2), 207-209. https://doi.org/10.1176/ps.62.2.pss6202_0206

Gregory, K. E., \& Radovinsky, L. (2012). Research strategies that result in optimal data collection from the patient medical record. Applied Nursing Research, 25(2), 108-116. https://doi.org/10.1016/j. apnr.2010.02.004

Hook, V., Brennand, K. J., Kim, Y., Toneff, T., Funkelstein, L., Lee, K. C., \& Gage, F. H. (2014). Human iPSC neurons display activity-dependent neurotransmitter secretion: Aberrant catecholamine levels in schizophrenia neurons. Stem Cell Reports, 3(4), 531-538. https://doi. org/10.1016/j.stemcr.2014.08.001

Hughes, J. R. (2010). Craving among long-abstinent smokers: An Internet survey. Nicotine \& Tobacco Research, 12(4), 459-462. https://doi. org/10.1093/ntr/ntq009

Kawai, A., Kurita, M., Nishino, S., Hirata, E., Sato, T., \& Okubo, Y. (2017). Need for medication to complement catecholamines in smoking cessation of hardcore smokers. Neuropsychiatric Disease and Treatment, 13, 2419-2424. https://doi.org/10.2147/NDT.S144181

Lawn, S., \& Pols, R. (2003). Nicotine withdrawal: Pathway to aggression and assault in the locked psychiatric ward? Australasian Psychiatry, 11(2), 199-203. https://doi.org/10.1046/j.1039-8562.2003.00548.x Leventhal, A. M., Ameringer, K. J., Osborn, E., Zvolensky, M. J., \& Langdon, K. J. (2013). Anxiety and depressive symptoms and affective patterns of tobacco withdrawal. Drug and Alcohol Dependence, 133(2), 324-329. https://doi.org/10.1016/j.drugalcdep.2013.06.015

Lewin, K. (1947). Frontiers in group dynamics: Concept, method, and reality in social science; social equilibria, and social change. Human Relations, 1(1), 5-41. https://doi.org/10.1177/001872674700100103

Leyro, T. M., Hall, S. M., Hickman, N., Kim, R., Hall, S. E., \& Prochaska, J. J. (2013). Clinical management of tobacco dependence in inpatient psychiatry: Provider practices and patient utilization. Psychiatric Services, 64(11), 1161-1165. https://doi.org/10.1176/appi.ps.201200574

McLaughlin, I., Dani, J. A., \& De Biasi, M. (2015). Nicotine withdrawal. In D. J. K. Balfour \& M. Munafò (Eds.), Current topics in behavioral neurosciences: The neuropharmacology of nicotine dependence (pp. 99-123). Cham, Switzerland: Springer. https://doi. org/10.1007/978-3-319-13482-6_4

Mendelsohn, C. (2013). Optimising nicotine replacement therapy in clinical practice. Australian Family Physician, 42(5), 305-309.

Mendelsohn, C. P., Kirby, D. P., \& Castle, D. J. (2015). Smoking and mental illness: An update for psychiatrists. Australasian Psychiatry, 23(1), 37-43. https://doi.org/10.1177/1039856214562076

Mittal, R., Debs, L. H., Patel, A. P., Nguyen, D., Patel, K., O'Connor, G., \& Liu, X. Z. (2017). Neurotransmitters: The critical modulators regulating gut-brain axis. Journal of Cellular Physiology, 232(9), 2359-2372. https://doi.org/10.1002/jcp.25518

Molyneux, A. (2004). Nicotine replacement therapy. British Medical Journal, 328(7437), 454-456. https://doi.org/10.1136/ bmj.328.7437.454

Myklebust, K. K., Bjørkly, S., \& Råheim, M. (2017). Nursing documentation in inpatient psychiatry: The relevance of nurse-patient interactions in progress notes-A focus group study with mental health staff. Journal of Clinical Nursing, 27(3-4), e611-e622. https://doi. $\operatorname{org} / 10.1111 /$ jocn.14108

Paolini, M., \& De Biasi, M. (2011). Mechanistic insights into nicotine withdrawal. Biochemical Pharmacology, 82(8), 996-1007. https://doi. org/10.1016/j.bcp.2011.07.075

Potenza, M. N. (2013). Neurobiology of gambling behaviors. Current Opinion in Neurobiology, 23(4), 660-667. https://doi.org/10.1016/j. conb.2013.03.004

Prochaska, J. J., Das, S., \& Young-Wolff, K. C. (2017). Smoking, mental illness, and public health. Annual Reviews, 38, 165-185. https://doi. org/10.1146/annurev-publhealth-031816-044618

Prochaska, J. J., Fletcher, L., Hall, S. E., \& Hall, S. M. (2006). Return to smoking following a smoke-free psychiatric hospitalization. The American Journal on Addictions, 15(1), 15-22. https://doi. org/10.1080/10550490500419011

Prochaska, J. J., Gill, P., \& Hall, S. M. (2004). Treatment of tobacco use in an inpatient psychiatric setting. Psychiatric Services, 55(11), 12651270. https://doi.org/10.1176/appi.ps.55.11.1265

Prochaska, J. J., Hall, S. E., Delucchi, K., \& Hall, S. M. (2014). Efficacy of initiating tobacco dependence treatment in inpatient psychiatry: A randomized controlled trial. American Journal of Public Health, 104(8), 1557-1565. https://doi.org/10.2105/AJPH.2013.301403 
Quit Victoria. [QuitVic]. (2017a, June 1). How does nicotine replacement therapy work [Video file]. Retrieved from https://youtu.be/ qfKPP36zgmQ

Quit Victoria. [QuitVic]. (2017b, June 1). Withdrawal: what is going on inside your body [Video file]. Retrieved from https://youtu. be/6DniAXFc8KA

Reynolds, G.P., McGowan, O. O., \& Dalton, C.F. (2013). Pharmacogenomics in psychiatry: The relevance of receptor and transporter polymorphisms. British Journal of Clinical Pharmacology, 77(4), 654-672. https://doi.org/10.1111/bcp.12312

Robson, D., Spaducci, G., McNeill, A., Stewart, D., Craig, T. J. K., Yates, M., \& Szatkowski, L. (2017). Effect of implementation of a smoke-free policy on physical violence in a psychiatric inpatient setting: An interrupted time series analysis. Lancet Psychiatry, 4, 540-546. https:// doi.org/10.1016/S2215-0366(17)30209-2

Schneider, N. G., Koury, M. A., Cortner, C., Olmstead, R. E., Hartman, N., Kleinman, L., \& Leaf, D. (2006). Preferences among four combination nicotine treatments. Psychopharmacology, 187(4), 476-485. https:// doi.org/10.1007/s00213-006-0449-5

Shiffman, S., Cone, E. J., Buchhalter, A. R., Henningfield, J. E., Rohay, J. M., Gitchell, J. G., \& Chau, T. (2009). Rapid absorption of nicotine from new nicotine gum formulations. Pharmacology, Biochemistry, and Behavior, 91(3), 380-384. https://doi.org/10.1016/j.pbb.2008.08.012

Shiffman, S., Shadel, W. G., Niaura, R., Khayrallah, M. A., Jorenby, D. E., Ryan, C. F., \& Ferguson, C. L. (2003). Efficacy of acute administration of nicotine gum in relief of cue-provoked cigarette craving. Psychopharmacology, 166(4), 343-350. https://doi.org/10.1007/ s00213-002-1338-1

Smith, P. M., Cobb, N., \& Corso, L. (2013). It's not that simple: Tobacco use identification and documentation in acute care. International Journal of Environmental Research and Public Health, 10(5), 20692083. https://doi.org/10.3390/ijerph10052069

Smith, P. H., Homish, G. G., Giovino, G. A., \& Kozlowski, L. T. (2014). Cigarette smoking and mental illness: A study of nicotine withdrawal. American Journal of Public Health, 104(2), e127-e133. https://doi. org/10.2105/AJPH.2013.301502

Soyster, P., Anzai, N. E., Fromont, S. C., \& Prochaska, J. J. (2016). Correlates of nicotine withdrawal severity in smokers during a smoke-free psychiatric hospitalization. Preventive Medicine, 92, 176-182. https://doi. org/10.1016/j.ypmed.2016.01.026

Stiebel, V. G., \& Nightengale, B. (2013). Medical illness in psychiatric patients in the emergency department. In L. S. Zun, L. G. Chepnik, \& M. N. S. Mallory (Eds.), Behavioral emergencies for the emergency physician (pp. 132-139). https://doi.org/10.1017/СBO9781139088077.022

Subramaniyan, M., \& Dani, J. A. (2015). Dopaminergic and cholinergic learning mechanisms in nicotine addiction. Annals of the New York Academy of Sciences, 1349(1), 46-63. https://doi.org/10.1111/ nyas.12871
The Joint Commission. (2017). Specifications manual for National Hospital Inpatient Quality Measures. Retrieved from https://www.jointcommission.org/specifications_manual_for_national_hospital_inpatient_ quality_measures.aspx

Thomas, M., \& Richmond, R. (2017). Addressing the arguments against implementation of smoke-free policies in psychiatric facilities. Journal of Psychiatric and Mental Health Nursing, 24(5), 322-331. https://doi. org/10.1111/jpm.12383

Tickle-Degnen, L. (2013). Nuts and bolts of conducting feasibility studies. American Journal of Occupational Therapy, 67(2), 171-176. https:// doi.org/10.5014/ajot.2013.006270

U.S. Department of Health and Human Services, Public Health Service. (2008). Clinical practice guideline: Treating tobacco use and dependence: 2008 update. Retrieved from https://www.ahrq.gov/sites/ default/files/wysiwyg/professionals/clinicians-providers/guidelines-recommendations/tobacco/clinicians/update/treating_tobacco_use 08.pdf

U.S. Department of Health and Human Services, Public Health Service. (2014). The health consequences of smoking-50 years of progress: A report of the Surgeon General, 2014. Retrieved from https://www.surgeongeneral.gov/library/reports/50-years-of-progress/full-report. pdf

West, R., \& Shiffman, S. (2001). Effect of oral nicotine dosing forms on cigarette withdrawal symptoms and craving: A systematic review. Psychopharmacology, 155(2), 115-122. https://doi.org/10.1007/ s002130100712

Wye, P. M., Stockings, E. A., Bowman, J. A., Oldmeadow, C., \& Wiggers, J. H. (2017). Effectiveness of a clinical practice change intervention in increasing the provision of nicotine dependence treatment in inpatient psychiatric facilities: An implementation trial. BMC Psychiatry, 17(56), 1-12. https://doi.org/10.1186/ s12888-017-1220-7

Yamamoto, K., Shinba, T., \& Yoshii, M. (2014). Psychiatric symptoms of noradrenergic dysfunction: A pathophysiological view. Psychiatry and Clinical Neurosciences, 68(1), 1-20. https://doi.org/10.1111/ pcn.12126

How to cite this article: Muladore E, Brown JA, Haefner J, Kupferschmid B. Improving patient education about tobacco withdrawal and nicotine gum use by registered nurses in inpatient psychiatry: A feasibility study. J Psychiatr Ment Health Nurs. 2018;25:496-505. https://doi.org/10.1111/jpm.12495 